\title{
Identifying and Preventing Threats to Academic Freedom
}

\author{
Brett J. Holt \\ University of Vermont, USA
}

\begin{abstract}
Socrates may have been the first documented academic that had one's academic freedoms infringed upon, but the threats continue today (albeit less dramatic than the public taking of one's own life). What is the purpose of academic freedom and why is it important for academics to be granted academic freedom? What are the current threats to academic freedoms? This paper will first seek to answer both of those questions from a discourse developed by Lehrfreiheit and Lernfreiheit [1] and held today by current academics. This paper will submit an overview of six ominous and pervasive threats to the academies: 1) Governance/Accreditation, 2) Academic Capitalism, 3) Special Interest, 4) Socialized Conformity, 5) Culture of Fear and 6) Expert Identity. Current examples and experiences will be provided in each category in order to orient the reader. When they occur, identified threats to academic freedoms arguably diminish the integrity of the profession; both academies and academics. The author will conclude by making suggestions to prevent these six threats to one's academy and their academic freedoms.
\end{abstract}

\section{Introduction}

Historically, several academics and educators have famously had their academic freedoms challenged. Names such as Socrates, Bruno, Galilee, and Scopes bring about unpleasant images. The consequences suffered by these academics have been less than agreeable. Socrates even notoriously committed suicide to preserve his integrity and his academic freedom. Early academics like Lehrfreiheit and Lernfreiheit [1], therefore, insisted that the academic should be allowed to teach topics that were appropriate and necessary to facilitate learning. Concurrently, they also reasoned that the academic needed freedom to pursue lines of inquiry that best led to their understanding of questions in their discipline/field of study, even if those lines of inquiry were considered by the general public to be restricted.
More recently, Nelson [2] provides characteristics that define academic freedom and this author has summarized in Table 1.

Table 1. Nelson's [2] Characteristics of Academic Freedom

\begin{tabular}{|l|l|}
\hline Academic Freedom Allows: & $\begin{array}{l}\text { Academic Freedom Does } \\
\text { Not: }\end{array}$ \\
\hline $\begin{array}{l}\text { Engagement in intellectual } \\
\text { debate without fear of } \\
\text { censorship. }\end{array}$ & $\begin{array}{l}\text { Allow one to threaten, } \\
\text { harass, intimidate, ridicule } \\
\text { or impose views on others. }\end{array}$ \\
\hline $\begin{array}{l}\text { Right to remain true to a } \\
\text { pedagogical philosophy and } \\
\text { intellectual commitments. }\end{array}$ & $\begin{array}{l}\text { Provide the right of non- } \\
\text { mastery of content. }\end{array}$ \\
\hline $\begin{array}{l}\text { Comparison/contrasts } \\
\text { between subject and any } \\
\text { field of human knowledge. }\end{array}$ & $\begin{array}{l}\text { Prevent other academics } \\
\text { from articulating their } \\
\text { disposition. }\end{array}$ \\
\hline $\begin{array}{l}\text { Faculty and students the } \\
\text { right to express views } \\
\text { without fear of sanction } \\
\text { unless it impairs the rights } \\
\text { of others. }\end{array}$ & $\begin{array}{l}\text { Protect from disciplinary } \\
\text { action (although does } \\
\text { guarantee "due process"). }\end{array}$ \\
\hline $\begin{array}{l}\text { Right to draw conclusions } \\
\text { on research that academics } \\
\text { engage. }\end{array}$ & $\begin{array}{l}\text { Protect from penalties } \\
\text { resulting from illegal } \\
\text { activity. }\end{array}$ \\
\hline $\begin{array}{l}\text { That political, } \\
\text { philosophical, and religious } \\
\text { beliefs cannot be imposed } \\
\text { on the academic. }\end{array}$ & $\begin{array}{l}\text { Permit one to ignore policy } \\
\text { or regulations (although } \\
\text { does allow for criticism). }\end{array}$ \\
\hline $\begin{array}{l}\text { Right of redress if rights } \\
\text { have been violated. }\end{array}$ & $\begin{array}{l}\text { Prevent disagreement with } \\
\text { processes and practices. }\end{array}$ \\
\hline $\begin{array}{l}\text { Protection from reprisal for } \\
\text { disagreeing } \\
\text { administrative policy. }\end{array}$ & $\begin{array}{l}\text { Protect the academic from } \\
\text { various sanctions (such as } \\
\text { denial of merit raises). }\end{array}$ \\
\hline $\begin{array}{l}\text { Right to challenge } \\
\text { alternative views (but not } \\
\text { penalize those that hold } \\
\text { them). }\end{array}$ & $\begin{array}{l}\text { Defend absenteeism of the } \\
\text { subject matter } \\
\text { skipping class). }\end{array}$ \\
\hline $\begin{array}{l}\text { The right to maintain } \\
\text { academic standards. }\end{array}$ & $\begin{array}{l}\text { Guarantee an unqualified } \\
\text { lifetime appointment. }\end{array}$ \\
\hline $\begin{array}{l}\text { Substantial latitude in the } \\
\text { teaching process. }\end{array}$ & $\begin{array}{l}\text { Shield from professional } \\
\text { misconduct. }\end{array}$ \\
\hline For "due process." & Protect from investigations. \\
\hline
\end{tabular}


The purpose of this manuscript is to identify six common threats that academics may experience in regards to their academic freedoms, provide examples that help in the identification of threats, and finally make suggestions on how to combat those threats. First, however, the scope of this paper will broadly discuss threats to academic freedoms occurring in six categories (1. Governance/Accreditation, 2. Academic Capitalism, 3. Special Interest, 4. Socialized Conformity, 5. Culture of Fear, and 6. Expert Identity).

\section{Governance/Accreditation}

Governance (sometimes, indirectly through a process known as accreditation) threatens academic freedoms. This author will approach governance and accreditation as the same threat to academic freedom, since it is difficult to maintain that they are different entities.

Eaton [3] informs the reader that public colleges/universities, in the United States of America (U.S.), undergo an accreditation processes for both the institution and independent programs. However, each of those accrediting bodies must, according to the Higher Education Act, 1965 and the General Education Provision Act, 1972, undergo their own review process by the U.S. Department of Education. That review occurs by the National Advisory Committee for Institute Quality and Integrity (an 18-member appointed body by U.S. Congress, U.S. Senate, and the U.S. Secretary of Education). Therefore, it is difficult to distinguish between the criteria set forth by the accrediting bodies and the criteria that is set by the federal government, since the accrediting bodies are accountable to government oversight. Eaton [3] reveals that the federal government did not always have such influence in the accreditation process. Instead, accreditation used to be a process that was conducted and managed by selfreview and peer-review. However, in the 1950's public academic institutions entered into an agreement with the federal government. Critics will point out that the arduous accreditation process has now become one of compliance rather than a process of review.

Government when inserting itself into the accreditation process, is often times to control. Baez [4] criticizes "requirements" placed upon accrediting bodies (and, then passed on to the institutions/programs) and indicates that they are meant to "dictate" or "control." Therefore, accrediting bodies (under government oversight) often "dictate" the objectives academics determine as valuable, the methodology in which an academic must teach, and often times the way academics assess their students. For example, many teacher-preparation colleges in the U.S. will require a standardized exam known as the Praxis Core in order to meet the demands of the Council for Accreditation of Educator Preparation (CAEP). Setting aside the severe criticism of the Praxis exam itself (which includes validation techniques of the questions), it needs to be understood that the exam is typically considered a "necessary" component that graduating teacherpreparation students need fulfill in order to keep the institution's teacher preparation accreditation and recognition; However, determination of Praxis Core as "necessary" was influenced and encouraged by CAEP (an accrediting organization monitored by the afore mentioned federal government's NACIQI).

The accreditation process, Baez [4] continues to explain, turns independent faculty employees into what resembles "assembly line workers." Instead of focusing on the more foundational and organic aspects of academia such as experimenting with teaching methodologies or exploring a line of inquiry, many faculty members are, then, reduced to employees that perform specific (to the accreditation process) tasks at specific times and in a specific order [4]. Most academics, it is surmised, neither received training in their preparation nor have a dispositional commitment to those "assembly line" type processes. Therefore, the accreditation process continues to handicap the college/university faculty by distancing them from their defined academic responsibilities (free inquiry, free service, and free teaching/learning) and placing them in a subservient position of tedious task accountancy.

Academics, therefore, should comprehend that often times curricular requirements are not the result of academically free decision making by faculty. Instead, many curricular requirements and decisions are a form of institutional/programmatic control over academics applied by governments and faculty employees are simply following the directives to avoid being considered insubordinate.

\section{Academic Capitalism}

Academic capitalism is when fiscal revenue is prioritized in academic decision-making rather than an academic foundational ethos. Academic capitalism can lead to infringements on the academic freedoms of both faculty and students. This author will examine two significant dangers of academic capitalism: 1) College/University Budget and 2) For-Profit Colleges.

\subsection{Budget}

The first danger of academic capitalism that this author will address is budget. Budgetary concerns have had a profound effect on the academic freedoms of college faculty and students. Bradley et al. [5] report on the 2010 recession-era budget crisis and effects that it had on colleges. While ten years old, the effects should not be dismissed given the current budgetary crisis occurring in relation to a (2020) world-wide pandemic. 
It is reported that the 2009-2010 recession caused the cancellation of academic programs at multiple public institutions of higher education in the U.S. For example, Louisiana State University cancelled several Foreign Language programs (including but not limited to: German, Swahili, Japanese, and Russian). Similarly, Winona State University (Winona, MN) also eliminated Foreign Language programs in French and German. Concurrently, the University of Southern Mississippi deactivated their programs in Marine Science, Art, Health, Geology, etc., while the University of Maine eliminated programs in Theatre, Public Administration, and Women's Studies [5].

In addition to program elimination, some colleges, when faced with budgetary shortfalls, engage in furloughs [5]. Furloughs can best be defined as mandatory "time-off" without pay. Furloughs often times have absurd rules attached to them such as not reading a book in your field of study or contacting your students on any day that you have been furloughed.

Bradley et al. report that many colleges and universities involved in mandatory furloughs and program discontinuation directed millions of dollars into non-academic endeavors such as athletics, dining facilities, campus community spaces, etc. Some colleges, while recording record number of revenues, pleaded with the academic faculty to take furloughs and salary cuts.

Currently, faculty at a Northeastern, state-flagship university are in negotiations with administration to take a five percent decrease in salary and programs/departments have been instructed to "freeze" all academic hiring due to an enrollment deficit caused by the current pandemic. However, at the same institution the athletic department has continued to hire new athletic coaches (even though athletic play has been suspended due to the afore mentioned pandemic) and building facilities have continued to supply buildings and every classroom with the latest technology hardware/software (including tablets, projectors, document cameras, dvd players, sound bars, etc.) even when not necessary to the classroom learning objectives or academic mission statements of the programs and university.

What message should academics infer if program elimination and faculty furloughs increase and/or salary/benefit decreases continue while increased budgets proceed for non-academic needs? Obviously, the elimination of academic programs limits academic freedom both in regards to student choice and faculty inquiry, not to mention potential resources for the faculty. While, loss of salary/benefits disincentivizes faculty.

\subsection{For-Profit College}

The second danger posed by academic capitalism is for-profit colleges. For-profit colleges have become a threat to academic freedom due to their fiscal orientation and disposition on higher education.

Yeoman [6] describes a "lifetime of debt," in which $22 \%$ of students enrolled in for-profit colleges/universities defaulted on their student loans. This is about three times more than the $7 \%$ default rate of students enrolled in not-for-profit colleges/universities. Thereby students, it can be assumed, enrolling in for-profit colleges default on more loans. Further, Yeoman [6] claims that $57 \%$ of students enrolled in for-profit colleges dropped out or failed to re-enroll within a three-year time period. Concurrently, it is reported that $31 \%$ of the average budget in for-profit colleges was used for recruiting. Unbelievably, recruiters at some for-profit schools were offered paid vacation trips if they met recruiting quotas. Then, in order to gain offered recruiting benefits, the recruiters would frequently misrepresent academic characteristics such as teaching qualifications, job placement statistics, degree completion time, and transfer credit in order to enroll a student. In one reported instance supplied by Natale et al. [7], the U.S. Government Accountability office, while furtively investigating the influx of GI Bill spending (Military Reimbursement) at for-profit colleges, found that admission officers often encouraged fraudulent practices such as claiming nonexistent dependents on their financial aid applications. Recruiters at for-profit colleges frequently sold an unrealistic "dream" of starting salaries after graduation. Students, therefore, post-enrollment at for-profit colleges, discovered that their degree programs were often not an academy-approved curriculum or the employment statistics given them were incorrect, etc.

Students who enrolled at for-profit colleges were more often likely to quit pursuing their degree program. And, in what amounts to a double penalty, were more likely to be denied future student loans in order to attend a more reputable program because they still had accrued debt from their enrollment at the for-profit schools.

For-profit colleges, then, maintain a focus on economic ends rather than the enrichment of a student's education [7]. If the student's education is not a priority then academic freedoms, too, are sacrificed in lieu of revenue.

\section{Special Interest}

Special interest groups have long had undue and unsolicited influence on academic freedoms. Many of those special interest groups are also un-monitored/ unsupervised regarding their involvement. 
The special interest or conflicts of interest often creates interference with academic freedoms. Websites like propublica.com keep track of conflicts of interest occurring in academics such as documenting instances of principle investigators awarded a grant and failing to disclose that they may also have an ownership investment in the product that they have been asked to investigate.

Numerous instances of high-profile corporations that have provided funding to academic researchers to study said company (i.e., British Petroleum provided funding to the University of South Alabama to study the effects of the Gulf Oil spill caused by their company) have been reported [8]. Another example of a conflict of interest in the academic setting was Brown University's questionable relationship with the pharmaceutical company SmithKlineBeecham/GlaxoSmithKline in studying the effects of a drug called Paxil (study 329). In this case, the primary investigator had received tens of thousands of dollars from the company and it is now speculated that the report may have been ghostwritten by an unidentified author [9]. Such examples call into question the ability to maintain "free inquiry" and practice of academic freedom amongst the faculties. In addition, these examples resulted in high-profile public skepticism of the academic research, provoking condemnation of academic integrity and the legitimacy of the academic programs involved. Consequently, when one group of academic researchers draw skepticism to their work, they also invite critics to dismiss more legitimate inquiry.

Special interest groups that insert themselves into academic research inquiry or classroom teaching (usually through funding), make it is easy for academics to remain skeptical regarding their motives. Motives are further called into question when media reports arise concerning special interest groups.

The author of this manuscript questions the purpose of the media's involvement when addressing and reporting on special interest groups' relationships with academics. When criticism is drawn to the conflicts of interest under scrutiny, does the media outlet have an obligation to report on the infringements to the academies? This author would speculate that, more often than not, the media typically sensationalizes the conflict of interest from the business standpoint while overlooking the importance to maintaining free inquiry at the academic institution thereby compounding the problems with public trust in academics. Regardless, the combination of sensationalized press surrounding special interest and the excess allure of funding provided by special interest will continue to affect academic freedoms when public faith continues to be lost.

\section{Socialized Conformity}

Socialized conformity is defined as a type of social influence that results in a change of behavior or belief in order to fit in with a group (society). In 2018, two U.S. news media outlets were critical of socialized conformity occurring on U.S. college campuses.

The first of two major media news outlets in the U.S. that this author will discuss is a CBS news editorial. In this editorial, Braver [10] questions if "free expression" currently exists on college campuses? "College campuses today aren't places for a civil exchange of ideas, but an intolerant world of political correctness [10]." Many colleges form policies in order to make employees and students feel "comfortable," despite the fact that it may sacrifice important academic freedoms such as speech. One only has to imagine that certain theories or philosophical concepts may not be allowed to be discussed in one's course/s due to the fact that it may challenge or "upset" someone else's predetermined social belief system. In other words, colleges/universities have become victims of their own policies to force social conformity.

Social conformity may not just be happening in the classroom or the meeting offices, but also happens at academic celebrations such as convocation and graduation events. There have been numerous reports of cancelled graduation speakers because certain groups of students and/or faculty do not agree with that person's dispositions on a particular topic. Ironically, the person may have been chosen to speak on a different topic entirely. For example, a high-ranking Judge and alumnus may have been asked to speak at a Law College on "successfully navigating the first year of legal practice" but was protested and cancelled by the students because of a ruling s/he provided involving an unrelated issue in a recently adjudicated case on eminent domain rights.

Braver [10] continues that over half $(54 \%)$ of college students in the U.S. report feeling "uncomfortable" or "afraid" to say what they believe in classes. Therefore, it is not just the faculty whose voices are being suppressed and expected to conform to a particular disposition. Academics who embrace tenets of academic freedom such as free inquiry, free expression, and free course design should find it frightening that those same tenets are dismissed so easily in order to make individuals "feel comfortable."

The second criticism regarding social conformity is provided by the Washington Post [11], which describes a disturbing and disproportional growth amongst college administrators as compared to both students and faculty. In fact, Will [11] reports that data collected by the Manhattan Institute saw an increase of $125 \%$ in administration at California colleges/universities while only seeing a $33 \%$ increase in growth of students and a $24 \%$ increase in growth of faculty over a ten year time 
period. Therefore, a disproportional growth exists concerning positions that Will cynically describes as "Academic Bureaucrats." And, what exactly do these "Academic Bureaucrats" do for their colleges? Many have intentionally ambiguous (vanity) titles that make it difficult to decipher exact roles and responsibilities. Rather, many of these positions exist to (micro)manage engineered or imaginary threats and social behaviors on the college campus. For example, in the U.S., upper administrators are often hired to attempt to manage the disposition of entire college social cultures (i.e., dress code) without regard to an academic culture (i.e., curricular design). Academics may feel "socially" hindered from stating their true feelings because it does not conform to the status quo as determined by these afore mentioned vanity positions. For instance, an Environmental Studies professor/researcher may fail to report collected data that challenges the overall disposition of the Environmental Studies department and/or "social" mission statement of the department/college.

Will [11] challenges the reader to look at their college/university employee make-up and determine if there currently exist non-faculty in ambiguouslyoperationalized positions? In addition, one may find that committees within the academic community are being attended (and votes occurring) by these nonacademics. The problem with such a scenario is that many college/universities that abide by academic freedom tenets are supposed to have a commitment to "faculty" governance; Yet, if non-faculty are attending meetings and voting on policies that affect the academic curriculum, then it must be viewed as an attempt to modify or compel conformity of the faculty.

Concurrently, there exist a threat of what this author cynically refers to as "pre-determined outcome" committees. It is likely that many faculty (or nonfaculty) are frequently "appointed" because of a predetermined disposition to serve on a committee that makes an academic decision. Thus, the illusion that some form of free choice was implemented in the decision, but in reality, the outcome had already been pre-determined due to the appointments made. Sometimes, the exact same individuals will inevitably be appointed to all decision-making committees. Further, one cannot be surprised to find that faculty with divergent dispositions are frequently declined offers to serve on such committees. Therefore, the "minority voice" often goes unheard. This suppression of the minority voice, according to Braver [10] and Will [11], is exactly what the administration desires, as it will no longer present a visible challenge to their administrative agendas and fiats.

Suppressing minority voice, while providing the illusion that it was conducted out of free choice, administrators are effectively manipulating the entire social atmosphere of a college or university. Consequently, by changing the social atmosphere, academic freedoms are altered and endangered.

\section{Culture of Fear}

Culture (or climate) of fear is defined as the concept of people inciting fear in public to achieve political or workplace goals through emotional biases. Academics are not immune from a workplace culture of fear.

Many employees in society believe they have experienced fear in the workplace and that fear has caused a barrier to their aspirations and success. Mellon [12] has described five major causes (fear generators) of a culture of fear in the workplace: 1) short-termism, 2) perfectionism, 3) intellectualism, 4) pugilism, and 5) hierarchism. Each of these generators have been used in academics to subdue freedoms. The Table 2 below helps to define and identify each of the fear generators.

Table 2. Mellon's [12] Fear Generator Descriptions

\begin{tabular}{|l|l|}
\hline Workplace Fear Generator & Description/Example \\
\hline 1. Short-termism & $\begin{array}{l}\text { Administrative short-term } \\
\text { goals and cuts limit long- } \\
\text { term planning leaving } \\
\text { academics feeling helpless } \\
\text { and initiative decreases. }\end{array}$ \\
\hline 2. Perfectionism & $\begin{array}{l}\text { Administrative push for } \\
\text { flawlessness leaves } \\
\text { academics depressed, afraid } \\
\text { of making mistakes, and } \\
\text { inability to be creative } \\
\text { (take-risks). }\end{array}$ \\
\hline 3. Intellectualism & $\begin{array}{l}\text { Administrative press for } \\
\text { intellectual decision } \\
\text { making while disregarding } \\
\text { emotional decision-making } \\
\text { leaves academics with a } \\
\text { severe lack of motivation. }\end{array}$ \\
\hline 4. Pugilism & $\begin{array}{l}\text { Encouraged competition } \\
\text { amongst peers (i.e., internal } \\
\text { grants) leads to the image } \\
\text { that someone is always a } \\
\text { "loser." }\end{array}$ \\
\hline 5. Hierarchism & $\begin{array}{l}\text { Necessary decisions often } \\
\text { get delayed for upper- } \\
\text { administrative approval. }\end{array}$ \\
\hline
\end{tabular}

Efron [13] concedes that fear can be a motivating factor; But, can also lead to poor decision making and create barriers to success in organizations. If a culture of fear exists in the workplace, employees often feel that their work is meaningless. Efron contends that if employees a) fear losing their job, b) find it difficult to present or articulate thoughts to organization leaders, and c) are uncomfortable disagreeing with co-workers, then a culture of fear exists. While Efron refers to the 
business environment, academics are no exception in experiencing the three traits. Unlike the business world, however, academics can often feel retaliation from administration in ways other than threats to their employment such as the tenure/promotion process, blind review process, and/or the job interview process.

Furedi [14] describes how academic relationships and inquiry are prevented due to a culture of fear. Similar to the critique provided by Will [11], in the earlier subsection titled Socialized Conformity, Furedi agrees that "controversy" was once a staple of college education. The author even reports that the President of the University of Chicago endorsed an academic disposition of "discomfort" being an intrinsic value to academics [11]. However, recent college administrators view "controversy" as damaging to the psychological well-being of the student. As a consequence, administrators have employed policies that marginalize or completely disregard controversial topics. In fact, Furedi [14] alludes to an actual policy at Xavier University (Cincinnati, $\mathrm{OH}$ ) that is designed to guide academics through controversial topics. Under such policies or guidelines academics are regularly informed that they need/should be attentive to assigned readings, the language/words they choose to use in lectures, etc. in order to prevent possible mental health trauma of a student. Therefore, since they are led to believe that they may harm the students" "mental health," faculty experience fear in relation to developing academic relationship with their students.

Young [15] provides us with a current example and specific warning on the culture of fear that was maintained at a large private university in the U.S. (Liberty University; Lynchburg, VA). Students and professors reported being fearful to speak out against the policy beliefs of the university's president. In Young's editorial, The university president engaged in a frequent practice of irrationally disciplining both students and faculty for speaking publicly about their political beliefs if they were contrary to the political beliefs of the university president. It is suggested, by Young, that on more than one occasion students and faculty were dismissed from the university if they expressed antithetical political beliefs not held by the university president. Accordingly, a very severe culture of fear had been created. That fear prevented the very basic principles of academic freedom from being maintained.

The author of this paper questions how many academics have experienced some form of suppression (either inquiry related, service related, or teaching/grading related) due to a perceived culture of fear? Union grievances throughout the U.S. frequently are rooted in perceived threats from the administration. Those threats could include threats to an academic's promotions, salary increases, appointments to committees and research teams, etc. If a culture of fear is allowed to persist in an academic community, then this author suggests that academics will choose not to exercise their freedoms.

\section{Expert Identity}

The final threat to academic freedom that this author will address is Expert Identity. Ericsson and Smith [16], Ericsson [17], Berliner [18], and Firestein [19] have all provided discourses on how to identify an expert. All experts are considered to have accumulated 10,000 (+) hours of engagement in their discipline. While 10,000 (+) engagement hours in the field may be the overwhelming accepted criteria for identifying an expert there are other discipline specific criteria that one must usually meet. Therefore, every discipline/profession implicitly identifies minimal criteria that would be considered in determining one's expertise [18, 19]. Other expert characteristics considered in academia would include, according to Holt [20], tenure/promotion, terminal degree in the field, visibility of work, juried scholarship, and type/amount of service to the discipline. If one does not have the minimal requirements as identified by each independent academic discipline, then one is not an expert.

Holt [20] advises against the dangers of misidentifying expertise or purposefully enabling false expertise. All too often, in academia there exists a false sense of expertise. And, repeatedly, students or faculty members may blindly follow the assertions of false experts because they themselves are ignorant of the discipline. For example, throughout most academic institutions, one can usually find a course that is not taught by an expert in the discipline simply because an instructor was needed to fill the course. In some instances, individuals will identify themselves as experts when they have not met the minimal criteria of being considered an expert (i.e., the minimal engagement hours or an earned degree in the field of study). For instance, one can frequently witness online profiles where there is no accountability for claiming expertise including unsupervised college/university faculty profiles.

False expertise can be enabled through either purposeful or accidental reasons. For instance, one might intentionally mislead others to believe in their false expertise by falsifying their résumé or curriculum vita. Or, one may be unintentionally led to believe a false expert because that person may hold a similar (but, not esoteric) degree.

One might notice, on other occasions, non-experts placed in administrative decision-making roles and they do not/will not utilize the true expert resources available from their subordinates. Not everyone with authority has expertise. Specifically, Holt [20] warns the reader against conflating expertise with authority. Many 
academics will concede their expertise to pacify authority figures (usually administration). This pacification of authority figures will lead to the repression of true expertise and result in the false image of authorities and experts being one in the same.

Academic freedoms will be infringed upon because the lay community will associate an expert incorrectly, if expert academics are continually misidentified. For example, if a medical professional is falsely identified then there could be severe health repercussions for a patient. Likewise, if an academic expert is misidentified, then there will likely be repercussions for both students and co-workers. Just as the entire medical profession could undergo increased scrutiny and criticism if a false expert were to be exposed, so to would the academic world. In other words, if we continue to enable false experts then the public trust that has been placed in academics will be eroded.

\section{Discussion}

Continued conversations are needed to occur amongst faculty in order to maintain alertness and awareness of current threats that academics may encounter. Academic faculty should be encouraged to disclose their unique experiences through academic fellowship opportunities and potentially share solutions. It is likely that new threats will continue to encroach upon the academic; However, through identification of these current six common threats to academic freedom, one can devise a tactical scenario in avoiding or defeating these threats. It is this author's belief that academic freedom must be preserved.

\section{Conclusion}

The specific purpose of this manuscript was to identify six common threats currently being posed to academic freedoms (1. Governance/Accreditation, 2. Academic Capitalism, 3. Special Interest, 4. Socialized Conformity, 5. Culture of Fear, and 6. Expert Identity) and offer possible solutions to combat those threats. All of these threats can be present at the same time and interaction between the threats can be taxing on academic freedom. Similar to the inferences of Ledeoux, et al. [21], this author concludes that academics will continually have to combat threats that erode their academic freedoms unless a shared disposition of commitment to academic freedom is established. Faculty need to stay alert to potential dangers and address them as they arise.

\section{Recommendations}

Ten recommendations have been prepared to help combat the six identified threats to academic freedoms:

1. Faculty should be involved in drafting policies committed to academic freedom.

2. Faculty need to be involved with their own governance. More importantly, faculty need to be directly involved with the selection of criteria to which their academic disciplines are being held accountable.

3. Budget concerns need to be faculty concerns: Faculty cannot casually disregard fiscal dilemmas while administrators address budgetary concerns that affect their teaching, curricula, and research. When budget is used as rationale for infringements on freedoms, this author suggests that open audits be performed within the college/university to eliminate fraudulent rationale.

4. Faculty need to be involved with educating society about the dangerous dispositions posed by for-profit colleges.

5. Limit potential conflicts of interest. Perhaps, faculties could establish a conflict of interest oversight committee within departments to monitor the amount of external influence on freedoms.

6. Eliminate the concept of "conformity," especially in regards to government and/or accrediting bodies. Faculty and students should be encouraged to express themselves independent of the group.

7. Articulate the importance of academic freedoms to media outlets and help the media understand the dangers posed by threats to academic freedom.

8. Hold administrators accountable for any climate or culture that they propagate on their campuses by exposing potential perils. Further, encourage a climate of freedom rather than fear. Academic freedoms should be the first priority at an academic institution and academics need to feel free to operate.

9. Define expertise and hold non-expert decisionmakers accountable to the decisions they make that influence your area of expertise.

10. Report violations or potential violations to professional academies. Solicit "Position Statements" from said professional academies concerning academic freedom. 


\section{References}

[1] Commager, H. S. (1963). 'The University and Freedom: Lehrfreiheit \& Lehrnfreiheit', The Journal of Higher Education 34(7), pp. 361-370.

[2] Nelson, C. (2010). 'Defining Academic Freedom', Inside Higher Education; https://insidehighered.com/views/2020/12 21/defining-academic-freedom (Access Date: December, 2010).

[3] Eaton, J. S. (2010). 'Accreditation and the Federal Future of Higher Education', American Association of University Professors; https://www.aaup.org/article/accreditation-andfederal-future-higher-education (Access Date: September/ October, 2010).

[4] Baez, B. (2009). 'Faculty Forum: Accreditation fatigue', American Association of University Professors; https://www.aaup.org/article/faculty-forum-accreditationfatigue (Access Date: May/June, 2009).

[5] Bradley, G., Brown, G., \& Ufot, N. (2011). 'Crisis in Public Higher Education', American Association of University Professors; https://www.aaup.org/article/crisis-pub lic-higher-education (Access Date: May/June, 2011).

[6] Yeoman, B. (2011). 'The High Price of For-Profit Colleges', American Association of University Professors; https://www.aaup.org/article/high-price-profit-colleges (Access Date: May/June 2011).

[7] Natale, S. M., Libertella, A. F., \& Doran, C. J. (2015). 'For-Profit Education: The Sleep of Ethical Reason', Journal of Business Ethics 126(3), pp. 415-421.

[8] Lea, R. (2010). 'BP, Corporate R \& D, and the University', American Association of University Professors; https://www.aaup.org/article/bp-corporate-rd-and-university (Access Date: November/December 2010).

[9] Heck, I. (2014). 'Controversial Paxil Paper Still Under Fire 13 Years Later', The Brown Daily Herald; https://brown dailyherald.com/2014/04/02/controversial-paxil-paper-stillunder-fire-13-years-later/ (Access Date: 2 April, 2014).

[10] Braver, R. (2018). 'A War of Words on College Campuses', CBS News; https://www.cbsnews.com/news/a-w ar-of-words-on-college-campuses/, (Access Date: 21 January, 2018).

[11] Will, G. (2018). 'Trigger Warning: An Embarrassing Fragility on College Campuses', Washington Post; https://ww w.washingtonpost.com/opinions/the-cult-of-fragility-oncollege-campuses/2018/09/12/1368b146-b5e7-11e8-a2c53187, (Access Date: 12 September, 2018).

[12] Mellon, L. (2018). 'Why Creating a Learning Culture is the Answer to Fear', Duke Corporate Education; http://www. dukrce.com/insights/why-creating-learning-culture-answerfear/ (Access Date: March, 2018).
[13] Efron, L. (2017). 'Do You Have a Culture of Fear?', Forbes; https://www.forbes.com/sites/louidefron/2017/09/25/ do-you-have-a-culture-of-fear-three-questions-to-ask/?sh-2de dae651435 (Access Date: 25 September, 2017).

[14] Furedi, F. (2018). 'The Campus Culture of Fear and Its Costs', City Journal; https://www.city-journal.org/html/camp us-culture-fear-and-its-costs-16095.html (Access Date: 3 August, 2018).

[15] Young, W. (2019). 'Inside Liberty University's Culture of Fear', Washington Post; https://www.washingtonpost.com/ outlook/2019/07/24/inside-liberty-universitys-culture-fearhow-jerry-falwell-jr-silences-students-professors-who-rejecthis-pro-trump-politics/?arc404=true (Access Date: 24 July, 2019).

[16] Ericsson, K. A. \& Smith, J. (1991). Toward a General Theory of Expertise: Prospects and Limits; Cambridge University Press: Cambridge, EN.

[17] Ericsson, K. A. (2008). 'Deliberate Practice and Acquisition of Expert Performance: A General Overview', Academic Emergency Medicine 15(11), pp. 988-994.

[18] Berliner, D. C. (1994). 'Expertise: The Wonders of Exemplary Performance', in John N. Mangieri \& Cathy Collins Block (Eds.) Creating Powerful Thinking in Teachers and Students; Holt, Rinehart, and Winston: Fort Worth, TX, pp.141-186.

[19] Firestein, S. (2012). 'Ignorance: How It Drives Science', Oxford University Press: Oxford, EN.

[20] Holt, B. J. (2019). 'Fabricated Expertise: A Risk to Educator Freedom', The International Journal for CrossDisciplinary Subjects in Education 10(4), pp. 4147-4153.

[21] Ledoux, M. W., Marshall, T., \& McHenry, N. (2010). 'The Erosion of Academic Freedom', Educational Horizons 88(4), pp. 249-256. 